\title{
Caesarean Section Scar Ectopic Pregnancy Presenting with Uterine Rupture: A Rare Case Report
}

\section{ABSTRACT}

Caesarean scar ectopic pregnancy is a rare form of pregnancy implanting on a caesarean scar and is considered a gynaecological emergency associated with scar rupture and increased incidence of maternal morbidity when complicated with haemorrhage. Scar pregnancy incidence being more common as there are increased caesarean deliveries nowadays. Here the authors present a case of 28-year-old female with caesarean section scar ectopic pregnancy with ruptured uterine scar and haemorrhage associated with haemodynamic collapse which has poor prognosis. Imaging plays a crucial role in early detection and helps the clinician in further management to reduce maternal morbidity and mortality.

Keywords: Caesarean scar pregnancy, Magnetic resonance imaging, Ultrasonography

\section{CASE REPORT}

A 28-year-old female presented to the Department of Radiodiagnosis for ultrasonography with a history of three months of amenorrhea complaining of pain in abdomen and vaginal bleeding since three days. On clinical examination, serum beta Human Chorionic Gonadotropin (HCG) was positive with signs of haemodynamic collapse. Patient had a past history of two prior caesarean sections. Patient underwent ultrasound and Magnetic Resonance Imaging (MRI). Pelvic ultrasound was done and showed a well-defined gestational sac with viable embryonic pole corresponding to eight weeks six days with foetal heart rate of 168 beats per minute and perigestational trophoblastic flow was noted in the lower uterine segment closely attached to anterior myometrium in the region of previous caesarean section scar. A $53 \times 32 \mathrm{~mm}$ sized large haematoma was noted in endometrial cavity [Table/Fig-1a-c].

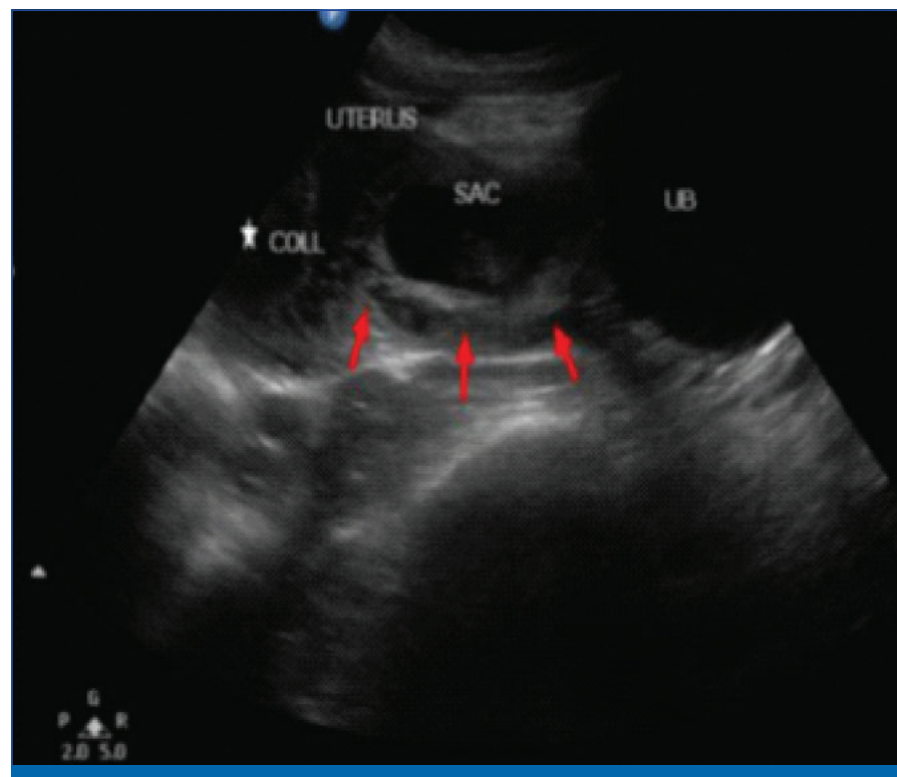

[Table/Fig-1a]: Shows a well-defined gestational sac with viable embryonic pole in the lower uterine segment closely attached to anterior myometrium in the region of previous caesarean section scar (red arrows). A large haematoma is noted in endometrial cavity.

On MRI, there was evidence of a gestational sac with embryonic pole seen in the lower uterine segment anteriorly bulging into the urinary bladder. There was loss of clear distinction between urinary bladder and uterus suggesting scar dehiscence. Bladder wall
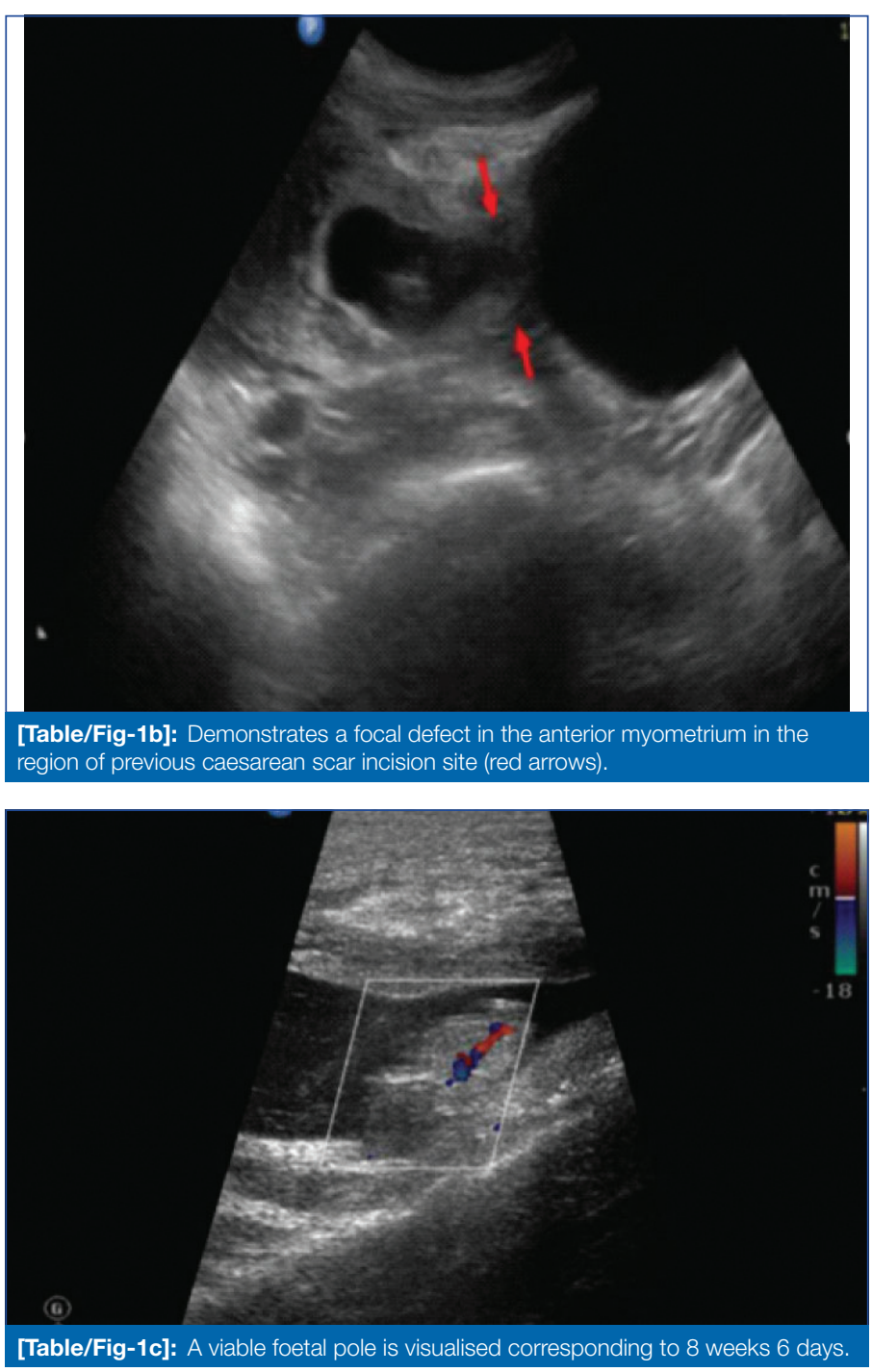

integrity was well maintained. Posterior myometrium appeared to be normal [Table/Fig-2a,b].

Intraoperatively there was a gestational sac adherent to thinned out caesarean scar suggesting dehiscence with haemorrhagic collection in endometrial cavity. Patient subsequently underwent hysterectomy [Table/Fig-3]. 


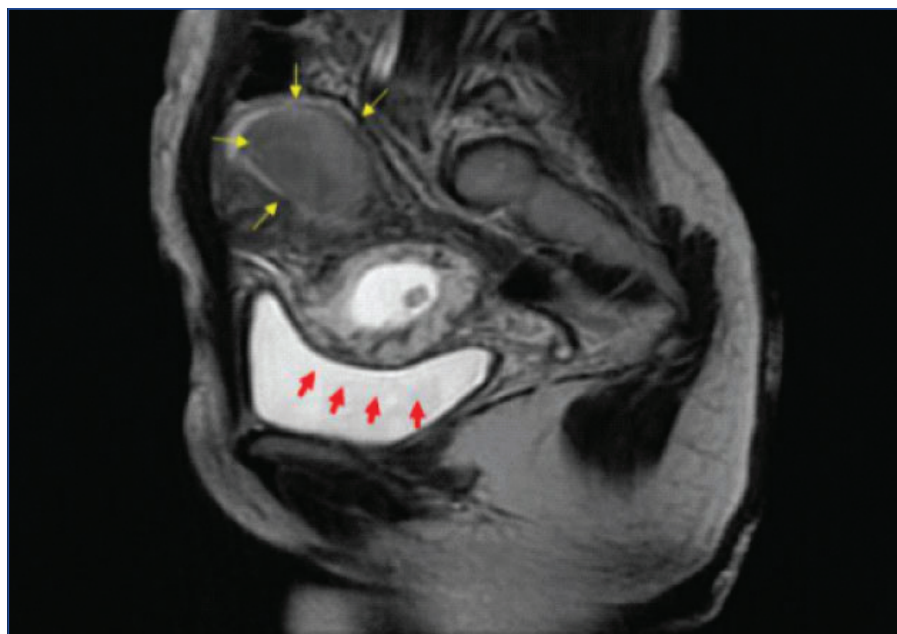

[Table/Fig-2a]: Sagittal T2 Weighted MRI showing a well-defined gestational sac with embryonic pole in the lower uterine segment. Loss of clear distinction between urinary bladder and uterus with anterior bulging of gestational sac into the urinary bladder and absence of surrounding myometrium suggesting scar dehiscence (red arrows). A large haematoma is noted in the endometrial cavity (yellow arrows).

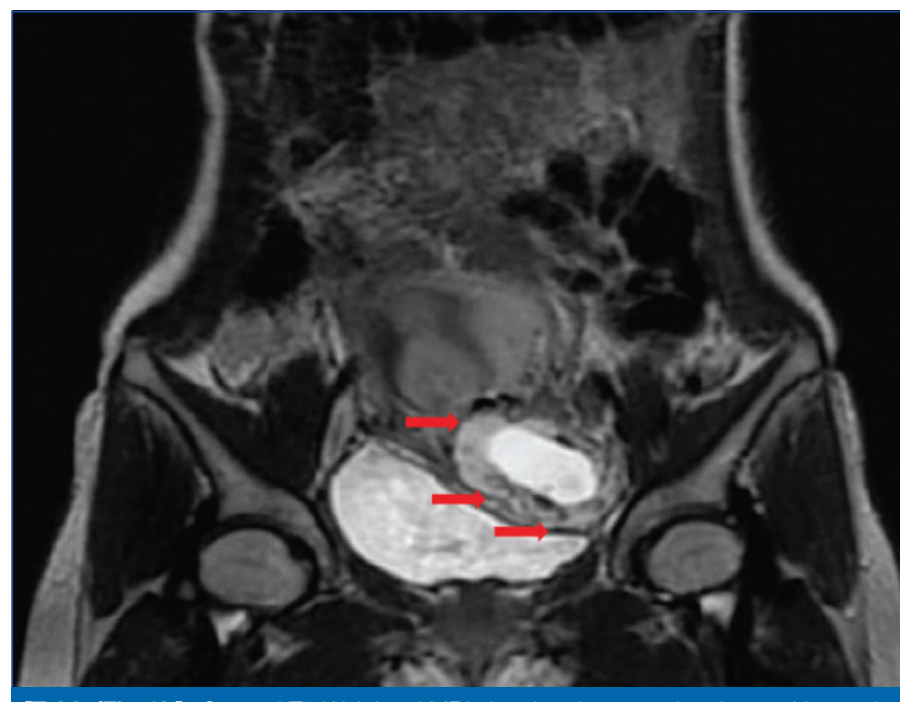

[Table/Fig-2b]: Coronal T2 Weighted MRI showing the gestational sac with good decidual reaction (red arrows) in lower uterine segment. However, urinary bladder wall integrity is well maintained.

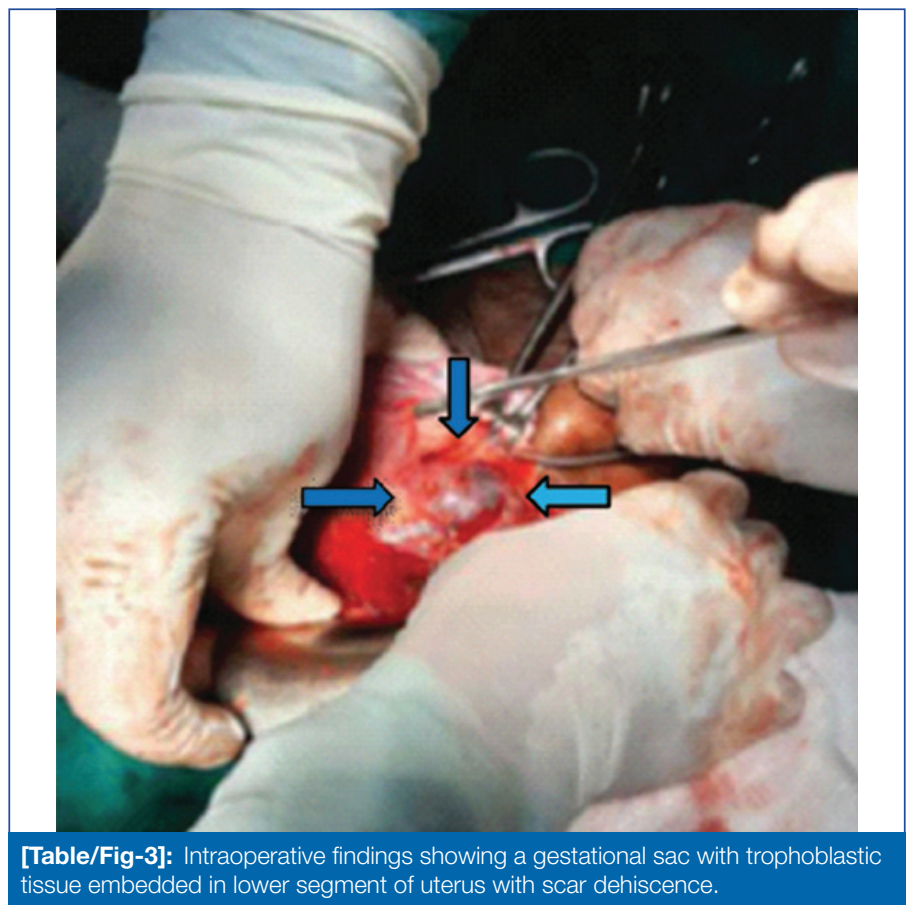

\section{DISCUSSION}

Caesarean Scar Pregnancy (CSP) is considered as a rare form of ectopic pregnancy and its prevalence ranges from 1 per 1800 and 1 per 2226 pregnancies. The CSP is caused by implantation of blastocyst within the lower uterine segment myometrial tissue of previous caesarean section scar site. Local myometrial and endometrial injury leads to poor vascularisation, fibrosis and improper healing forming a tract between the scar site and endometrial cavity leading to implantation of gestational sac at the incision site [1]. As pregnancy progresses, placenta gets invaded into the myometrium leading to Placenta praevia and Placenta accreta [2]. Based on the depth of invasion, there are two types of caesarean scar ectopic pregnancy. Type 1: The implanted blastocyst grows towards the uterine cervix. This type of CSP can progress to viable birth in third trimester but has an increased risk of massive postpartum haemorrhage from the site of implantation leading to maternal death. Type 2: The implanted blastocyst grows towards the uterine serosa and urinary bladder leading to increased risk of rupture and haemorrhage during early pregnancy [3].

Ultrasonography remains the initial imaging modality. However, $\mathrm{MRI}$ helps to confirm the diagnosis. Real-time ultrasonography is considered as safe, inexpensive, non-invasive with no radiation exposure. Ultrasonography findings demonstrate empty uterus and cervical canal with gestational sac embedded in the previous scar site with thinned out myometrium (myometrial thickness $<5 \mathrm{~mm}$ ) [4]. In few cases, there is a loss of clear distinction between outer surface of uterus and urinary bladder suggesting uterine rupture. Colour doppler is used to demonstrate the perigestational trophoblastic flow showing high velocity (Peak systolic velocity $>20 \mathrm{~cm} / \mathrm{sec}$ ) with low impedance flow (Pulsatility index $<1$ ) and viability [5]. The CSP can lead to complications such as uterine rupture and haemorrhage, hysterectomy and circulatory collapse eventually leading to maternal death [6].

The MRI provides an accurate information due to excellent soft tissue resolution by evaluating gestational sac location and myometrial invasion. Gestational sac can be seen embedded in the anterior myometrium of uterus. Focal outbulging of uterine contour can lead to scar rupture and haemorrhage with loss of normal myometrialplacental interface [7]. Anterior myometrial wall thickness can be measured on $\mathrm{MRI}$ and is helpful for further management. The 3D-transvaginal ultrasound can evaluate thinned out myometrium surrounding the sac and bladder-serosa interface. Ultrasound can also be used for guiding local methotrexate injection and curettage. Contrast-Enhanced Ultrasound (CEUS) is used in evaluation of real time blood perfusion of gestational sac [8].

Ultrasonographic criteria to diagnose CSP include: 1) empty uterine cavity; 2) location of trophoblast at the site of previous caesarean scar, mainly between urinary bladder and anterior uterine wall; 3) thin or absent myometrium between the gestational sac and the urinary bladder; 4) discontinuity in the anterior uterine wall on a sagittal section running that courses through the amniotic sac; 5) empty endo-cervical canal [9]. Transvaginal sonography is considered as the diagnostic imaging modality as it confirms the diagnosis of CSP by evaluating the location, gestational age and viability of pregnancy within the scar. "Sliding organ sign" can be demonstrated in CSP and is indicated by displacement or collapse of gestational sac into the cervical canal by applying compression with transvaginal probe, helps to rule out cervical pregnancy and spontaneous abortion [10]. Interventional radiological procedures like Uterine Artery Embolisation (UAE) helps in early management of such cases to reduce life threatening complications like haemorrhage and hypovolemic shock. Deepika TG and Wahi S had done a case report on caesarean scar ectopic pregnancy. However, they did not demonstrated the signs of uterine scar rupture on imaging which was discussed in the present study [11]. Another case presented by Gumdal S and Lakavath RD reported an irregular gestational sac with foetal node and discussed only ultrasonography findings which did not included Doppler and MRI findings to confirm the diagnosis of scar rupture as in the present study [12]. The present case presented with a gestational sac implanted in the 
previous caesarean section scar site and was associated with uterine rupture and haematoma in endometrial cavity which is considered as an uncommon presentation subsequently leading to potentially lifethreatening conditions like haemorrhage, hypovolemic shock and can eventually progress to maternal mortality.

\section{CONCLUSION(S)}

Ruptured CSP is an unusual presentation of ectopic pregnancy associated with massive haemorrhage and hysterectomy leading to maternal morbidity and mortality, hence prompt and timely diagnosis helps in early management, preventing catastrophic complications. Ultrasonography and MRI plays a key role in diagnosis.

\section{REFERENCES}

[1] Osborn DA, Williams TR, Craig BM. Caesarean scar pregnancy: Sonographic and magnetic resonance imaging findings, complications, and treatment. J Ultrasound Med. 2012;31(9):1449-56.

[2] Riaz RM, Williams TR, Craig BM, Myers DT. Caesarean scar ectopic pregnancy: Imaging features, current treatment options, and clinical outcomes. Abdominal Imaging. 2015;40(7):2589-99.
[3] Gonzalez N, Tulandi T. Caesarean scar pregnancy: A systematic review. J Minim Invasive Gynaecol. 2017;24(5):731-38.

[4] Hoffman T, Lin J. Caesarean scar ectopic pregnancy: Diagnosis with ultrasound Clin Pract Cases Emerg Med. 2020;4(1):65.

[5] Rotas MA, Haberman S, Levgur M. Caesarean scar ectopic pregnancies: Etiology, diagnosis, and management. Obstet Gynaecol. 2006;107(6):1373-81.

[6] Selvaraj LR, Rose N, Ramachandran M. Pitfalls in ultrasound diagnosis of caesarean scar pregnancy. The Journal of Obstetrics and Gynaecology of India. 2018;68(3):164-72.

[7] Wu R, Klein MA, Mahboob S, Gupta M, Katz DS. Magnetic resonance imaging as an adjunct to ultrasound in evaluating caesarean scar ectopic pregnancy. J Clin Imaging Sci. 2013;3:16.

[8] Liu D, Yang M, Wu Q. Application of ultrasonography in the diagnosis and treatment of caesarean scar pregnancy. Clinica Chimica Acta. 2018;486:291-97.

[9] Ajong AB, Kenfack B, Agbor VN, Njotang PN. Ruptured caesarean scar ectopic pregnancy: A diagnostic dilemma in a resource-limited setting. BMC Research Notes. 2018;11(1):01-05.

[10] Jayaram PM, Okunoye GO, Konje J. Caesarean scar ectopic pregnancy: Diagnostic challenges and management options. The Obstetrician \& Gynaecologist. 2017;19(1):13-20.

[11] Deepika TG, Wahi S. A rare case report of caesarean scar ectopic pregnancy. Journal of clinical and diagnostic research: JCDR. 2017;11(8):QD10.

[12] Gumdal S, Lakavath RD. A rare case report of scar ectopic pregnancy. Journa of Dr. NTR University of Health Sciences. 2020:9(4):270.

\section{PARTICULARS OF CONTRIBUTORS}

1. Resident, Department of Radiology, Shri B.M. Patil Medical College, Vijayapura, Karnataka, India

2. Associate Professor, Department of Radiology, Shri B.M. Patil Medical College, Vijayapura, Karnataka, India.

\section{NAME, ADDRESS, E-MAIL ID OF THE CORRESPONDING AUTHOR:}

Dr. PN Bhavani,

Room B12, NRI PG Hostel, BLDE Campus, Aashram Road,

Vijayapura, Karnataka, India.

E-mail: doc.pnb@gmail.com

AUTHOR DECLARATION:

- Financial or Other Competing Interests: None

- Was informed consent obtained from the subjects involved in the study? Yes

- For any images presented appropriate consent has been obtained from the subjects.
PLAGIARISM CHECKING METHODS: [Jain Het al.]

- Plagiarism X-checker: Nov 19, 2020

- Manual Googling: Mar 27, 2021

- iThenticate Software: May 26, 2021 (14\%)
ETYMOLOGY: Author Origin

Date of Submission: Nov 17, 2020

Date of Peer Review: Jan 16, 2021

Date of Acceptance: May 06, 2021

Yes

Date of Publishing: Oct 01, 2021 